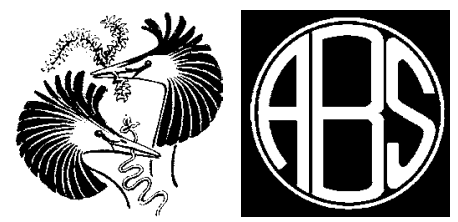

\title{
Stability and group specificity of stereotyped whistles in resident killer whales, Orcinus orca, off British Columbia
}

\author{
RÜDIGER RIESCH*, JOHN K. B. FORD† \& FRANK THOMSEN* \\ *Biozentrum Grindel, Universität Hamburg \\ $\dagger$ Pacific Biological Station, Fisheries and Oceans Canada, Nanaimo \\ (Received 14 August 2004; initial acceptance 18 October 2004; \\ final acceptance 15 March 2005; published online $\mathbf{\square} \mathbf{\square}$; MS. number: 8243R)
}

\begin{abstract}
Resident killer whales off British Columbia form four acoustically distinct clans, each with a unique dialect of discrete pulsed calls. Three clans belong to the northern and one to the southern community. Resident killer whales also produce tonal whistles, which play an important role in close-range communication within the northern community. However, there has been no comparative analysis of repertoires of whistles across clans. We investigated the structural characteristics, stability and group specificity of whistles in resident killer whales off British Columbia. Acoustic recordings and behavioural observations were made between 1978 and 2003. Whistles were classified spectrographically and additional observers were used to confirm our classification. Whistles were compared across clans using discriminant function analysis. We found 11 types of stereotyped whistles in the northern and four in the southern community with some of the whistle types being stable over at least 13 years. In northern residents, 10 of the 11 whistle types were structurally identical in two of the three acoustic clans, whereas the whistle types of southern residents differed clearly from those of the northern residents. Our study shows that killer whales that have no overlap in their call repertoire use essentially the same set of stereotyped whistles. Shared stereotyped whistles might provide a community-level means of recognition that facilitates association and affiliation of members of different clans, which otherwise use distinct signals. We further suggest that vocal learning between groups plays an important role in the transmission of whistle types.
\end{abstract}

(C) 2005 The Association for the Study of Animal Behaviour. Published by Elsevier Ltd. All rights reserved.

Vocal signals have become a paramount model system for studies of the evolution of behaviours. This is especially true in songbirds, pinnipeds and cetaceans where vocal signals are not encoded genetically but learned socially (Mundinger 1980; Cavalli-Sforza \& Feldman 1981; Janik \& Slater 1997; Tyack \& Sayigh 1997). Socially learned sounds are often defined as vocal traditions which can be stable for several generations (Mundinger 1980). Particularly in cetaceans, social structure and affiliation of individuals have a profound influence on those traditions. Bottlenose dolphins, Tursiops truncatus, for example, that live in

Correspondence: F. Thomsen, Biozentrum Grindel, Arbeitsbereich Ethologie, Universität Hamburg, Martin-Luther-King-Platz 3, D-20146 Hamburg, Germany (email: drthomsen@web.de). R. Riesch is now at the Department of Zoology, University of Oklahoma, 730 Van Vleet Oval, Norman, OK 7301, U.S.A. J. K. B. Ford is at the Cetacean Research Program, Pacific Biological Station, Fisheries and Oceans Canada, 3190 Hammond Bay Road. Nanaimo, B.C. V9T 6N7, Canada. fission-fusion societies, produce highly stereotyped and individual-specific 'signature whistles' which are thought to function as cohesion signals between individuals (Caldwell et al. 1990; Sayigh et al. 1990; Smolker et al. 1993; Tyack \& Sayigh 1997; Janik \& Slater 1998; Cook et al. 2004; but see McCowan \& Reiss 2001). Despite their individual distinctiveness, signature whistles of particularly bonded individuals are structurally similar, suggesting that vocal learning is concurrent with affiliative relationships (Watwood et al. 2004). On the other hand, sperm whales, Physeter macrocephalus, and killer whales, Orcinus orca, which live in stable groups, have distinctive groupspecific vocal repertoires called dialects (Ford \& Fisher 1983; Ford 1991; Strager 1995; Weilgart \& Whitehead 1997; Yurk et al. 2002; Rendell \& Whitehead 2004).

The dialects of resident killer whales off Vancouver Island, British Columbia have been studied intensively (Ford \& Fisher 1983; Ford 1991; Deecke et al. 2000; Miller et al. 2004). This population is divided into northern and southern resident communities. The two communities 
occupy overlapping adjacent ranges, but individuals from different communities have not been observed interacting. Resident killer whales feed on fish and live in stable matrilineal groups without dispersal (Bigg et al. 1990; Ford et al. 2000). Within both communities, related matrilines often associate on a regular basis and are therefore termed pods (Bigg et al. 1990; Ford et al. 2000). Each pod has a specific repertoire of 7-17 discrete burst-pulsed calls (Ford 1991). Certain pods share a portion of their call repertoires and are grouped into acoustical clans, of which there are three in the northern and one in the southern community. Discrete calls are the predominant sound type during periods of group dispersion, such as foraging and travelling, indicating that they are used to maintain contact between members of the matriline (Ford \& Fisher 1983; Ford 1989; Miller \& Bain 2000; Miller 2002; Miller et al. 2004). They might also be indicators of group affiliation (Ford 1989, 1991). Behavioural and genetic studies have provided evidence that dialects of discrete calls are learned rather than inherited genetically (Ford 1991; Barrett-Lennard 2000; Yurk et al. 2002). There is also evidence that vocal learning is not limited to vertical transmission from mother to offspring, but also takes place between matrilines with similar dialects (Deecke et al. 2000).

Another main carrier in underwater communication of resident killer whales comprises tonal sounds called whistles (Ford 1989), which are physically and aurally very easily distinguishable from pulsed calls. Structural measurements indicate that they are much more complex than those described for other delphinids (Thomsen et al. 2001). In northern resident killer whales, whistles are produced predominantly during socializing and social travelling when whales from the same clan or from different clans are interacting at close range. During socializing, they are the predominant sound type and might fulfil an important function as affiliative signals (Ford 1989; Thomsen et al. 2002). These findings strongly suggest that whistles are important not only in communication within the group but also between groups of different clans. It is therefore possible that the transmission of whistles, in contrast to those of discrete calls, is not restricted to groups with related dialects. However, the study of whistle structure in wild killer whales is still in its infancy. Ford (1989) reported a great variety of whistle forms but made no attempt to define structural categories. Hoelzel \& Osborne (1986) described four stereotyped whistles in southern residents that were stable over a period of 3 years and Thomsen \& Ford (1999) found evidence for stereotyped whistles within one clan of the northern resident community. However, there has been no detailed and comparative analysis of repertoires of whistles across different clans of resident killer whales.

In the present study we produced a structural classification of whistles in resident killer whales off Vancouver Island, British Columbia. We examined the structural characteristics of the northern whales' whistles over time and compared whistle repertoires of acoustical clans within the northern resident community as well as between northern and southern resident clans.

\section{METHODS}

\section{Study Population and Data Collection}

Our main study animals belonged to the northern resident community of killer whales that ranges from mid-Vancouver Island north to southeastern Alaska and comprises 216 individuals in 33 matrilines (1999 census, Ford et al. 2000). The smaller southern resident community is found seasonally around the southern tip of Vancouver Island and the Puget Sound area and comprises 87 individuals in 20 matrilines. Based on call similarities, the northern residents are grouped into three distinct clans: A-clan is by far the largest, followed by G-clan and the smallest is the R-clan. All southern residents are grouped into a single clan, called J clan (Ford \& Fisher 1983; Ford 1991).

Acoustic recordings and surface behaviour observations of northern resident killer whales were made in western Johnstone Strait and adjacent waters, British Columbia $\left(50^{\circ} 30^{\prime} \mathrm{N}, 126^{\circ} 35^{\prime} \mathrm{W}\right)$ from July to October 1996 and 1997 , from July to September 2001 and from August to September 2003. Most data were obtained from 20-m motor vessels on 3-9-h-long commercial whale-watching excursions based from Telegraph Cove and Port McNeill (northern Vancouver Island). In addition, some recordings were obtained from small $(<5 \mathrm{~m})$ outboard-powered inflatables and motorboats. A total of 281 excursions were undertaken with more than $1300 \mathrm{~h}$ spent at sea. Killer whales were observed on 254 field excursions with a total of $>250 \mathrm{~h}$ observation time. Individuals were identified by visual inspection of natural markings on the dorsal fin and back (Ford et al. 1994, 2000). All identifications were confirmed by three land-based observation stations and one visual and acoustic monitoring station in the vicinity of Johnstone Strait. Underwater sounds were recorded with a Bruel \& Kjaer 8101 hydrophone in 1996, an Offshore Acoustics hydrophone in 1997 and 2003, and a DEEPSEA Powerlight hydrophone (SM $1000 \mathrm{~S} / \mathrm{N}$ 153) in 2001 (sensitivity $-180 \mathrm{~dB}$ re $1 \mathrm{~V} / \mathrm{Pa}$ or greater). Recordings were made with Sony TCD-D8 (1996) and Sony TCD-D7 (1997) DAT-recorders and a Sony WMD-6C analogue cassette recorder (2001 and 2003). Frequency responses of the systems were $20 \mathrm{~Hz}$ to $18 / 20 \mathrm{kHz}( \pm 1 \mathrm{~dB})$. Simultaneous voice recordings of behavioural observations were made on a separate track of the same tape.

\section{Additional Data}

For the northern residents, we also used recordings obtained between 1978-1983 and 1993-1999 by J.K.B.F. Recordings of southern residents were also obtained by J.K.B.F. between 1979 and 1982. Details of recording equipment and methodology are given in Ford (1989, 1991). V. B. Deecke provided additional tapes of northern residents obtained between 1999 and 2001.

\section{Ethical Note}

All fieldwork for this study was observational and noninvasive. During recordings and visual identifications from boats, great care was taken to minimize disturbance 
of whales by adhering to British Columbia whalewatching guidelines (see Ford et al. 2000 for details). This involved maintaining a minimum distance of $100 \mathrm{~m}$ from the animals and never positioning the boat directly in the path of travelling groups or individuals. There were no signs of disturbance to the whales. Research was done in collaboration with the Canadian Department of Fisheries and Oceans under valid research permits where required.

\section{Initial Classification of Whistles}

Since in northern residents whistles are almost entirely associated with close-range behaviours (Ford 1989; Thomsen et al. 2002), we concentrated the classification effort on recordings of two behavioural categories, social travelling and socializing (defined after Ford 1989; Barrett-Lennard et al. 1996; Thomsen et al. 2002). During social travelling, whales swim in one closely knit group on a consistent course at $3-6 \mathrm{~km} / \mathrm{h}$ and engage sporadically in physical interactions or in surface activities such as flipper or fluke slapping. During socializing, whales group together, often in body contact, and engage in social interactions and aerial displays such as breaching, flipper and fluke slapping, chasing each other, rolling over each other, and sexual interactions. For the initial classification, we used real-time spectrographic analysis (RTS, version 2.0, Engineering Design Inc., Belmont, MA, U.S.A.; sample rate $=50 \mathrm{kHz}$, frequency range $=0-20 \mathrm{kHz}$, dynamic range $=42 \mathrm{~dB}$, fast Fourier transform, FFT, size $=512$ points). Approximately 6000 whistles were inspected visually during real-time spectrographic analysis. For each whistle, an ideogram indicating the fundamental frequency contour was drawn. We classified whistles according to their spectrographic contour. Stereotyped whistles were repetitive with a distinct spectrographic contour and were classified alphanumerically as W1 (whistle type 1), W2 and so on. Depending on the presence of frequency modulations, we further divided the main whistle types into subtypes. Whistles that were nonrepetitive were classified as variable whistles.

We analysed the structural parameters of 390 stereotyped whistles from 1978-2003 that could unambiguously be ascribed to a single acoustical clan and had a good signal to noise ratio; for this we used the bioacoustic software program SIGNAL, version 3.0 (Engineering-Design Inc.; FFT size $=512$ points, frequency resolution $=98 \mathrm{~Hz}$, time resolution $=10.2 \mathrm{~ms}$ ). From the fundamental frequency of each of these whistles we measured, with the onscreen cursor, the parameters start frequency, end frequency, minimum frequency, maximum frequency, bandwidth, duration and number of frequency modulations. Following Steiner (1981), we defined frequency modulations as changes of direction in the fundamental frequency from positive (rising) to negative (falling) and vice versa. To determine the carrier frequency, we used a special function of the SIGNAL software.

\section{Test of Interobserver Reliability}

We used a subset of 100 randomly chosen whistles to confirm our initial classification of the main categories after a method developed by Janik (1999). Spectrograms of the whistles were calculated using SIGNAL, version 3.0 (Engineering Design Inc; 1024 FFT size, frequency resolution, DF $=48.8 \mathrm{~Hz}$ and time resolution, DT $=20.5 \mathrm{~ms}$ ) and printed on separate sheets each of $13 \times 17 \mathrm{~cm}$. Five additional observers were asked to classify whistles independently by their shape. These observers were students of an experimental ethology course and had basic experience in classifying bird sounds. The spectrograms were presented in random order and each observer was allowed to categorize them into as many classes as appropriate. Afterwards, these classes were searched for common whistle types classified by all observers. We then used Kappa statistics to test for interobserver reliability (Siegel \& Castellan 1988).

\section{Stability of A-Clan Whistles}

Minimum frequency, maximum frequency, bandwidth, whistle duration, carrier frequency and frequency modulations of each whistle type were compared between A-clan recordings from 1978-1983 and 1996-1997. Because the data set of whistles from 2001 and 2003 was too small, it was not included in this analysis. Distributions of stereotyped whistle parameters were tested for normality with a Kolmogorov-Smirnov goodness-of-fit test. The MannWhitney $U$ test was used if the normality test failed. If the normality test succeeded, the data were analysed with the $t$ test. All presented $P$ values are two tailed.

\section{Group Specificity of Whistle Types}

For the majority of the whistle types, the same parameters and statistical methods were used as described above. However, if statistically significant differences were found in the comparison of A-clan whistle parameters from 1978-1983 and 1996-1997, the A-clan whistle parameters were not pooled, but tested independently with the corresponding G-clan data. For this, we conducted an analysis of variance. In cases of normal distribution and equal variance, the three groups were compared using one-way ANOVA. We used a Kruskal-Wallis ANOVA on ranks if data were not normally distributed.

\section{Comparison of Whistle Types Across Communities}

Initial classification and parameter measurements for southern resident whistles were made as described above for northern residents. Whistle types of southern residents were alphanumerically classified as SW1, SW2 and so on. A total of 435 measured whistles of the northern and southern whales were used in SPSS (for Windows, version 12.0, SPSS Inc., Chicago, U.S.A.) discriminant function analysis. We chose a stepwise comparison to determine 
the best discriminating variables of the eight parameter variables. To indicate the discriminating power of each variable, we computed Wilk's lambda and an appropriate $F$ statistic (a small Wilk's lambda indicates good discriminating ability). For each group the percentage of correct classification was given, with misclassified data being put in the most appropriate group. As grouping variables we used (1) whistle types, (2) acoustical clans and (3) resident communities.

\section{RESULTS}

\section{Stereotyped Whistles in Northern Residents}

Most whistles appeared to be variable in structure with no apparent similarities in spectrographic contour. Variable whistles ranged in frequency from 2.4 to $18.5 \mathrm{kHz}$, with durations of $0.06-18$ s. Physical characteristics are described in more detail in Thomsen et al. (2001). However, some whistles were very stereotyped and repetitive, and could be classified into six discrete categories based on structure. We found 1739 stereotyped whistles in the recordings from 1978-2003. Figure 1 shows examples of spectrograms of the whistle types recorded in different years. Five of the categories were further divided into two subcategories because of differences in the last whistle segment. These subcategories were labelled with the index $\mathrm{T}$ (in subscript) indicating a trill-like ending. The parameter measurements of the 390 selected stereotyped whistles revealed a high consistency in spectrographic shape; however, whistle types varied to some extent in duration and certain frequency parameters (Table 1, Fig. 1).

\section{Classification by Human Observers}

The visual inspection method showed that observers generally agreed on the classification of stereotyped whistles. If only stereotyped whistle types were considered and all others were considered as a single residual class, the degree of interobserver reliability was very high (Kappa statistic: $\kappa=0.78, Z=16.9, P<0.0001$; Table 2). However, Table 2 shows that up to two observers
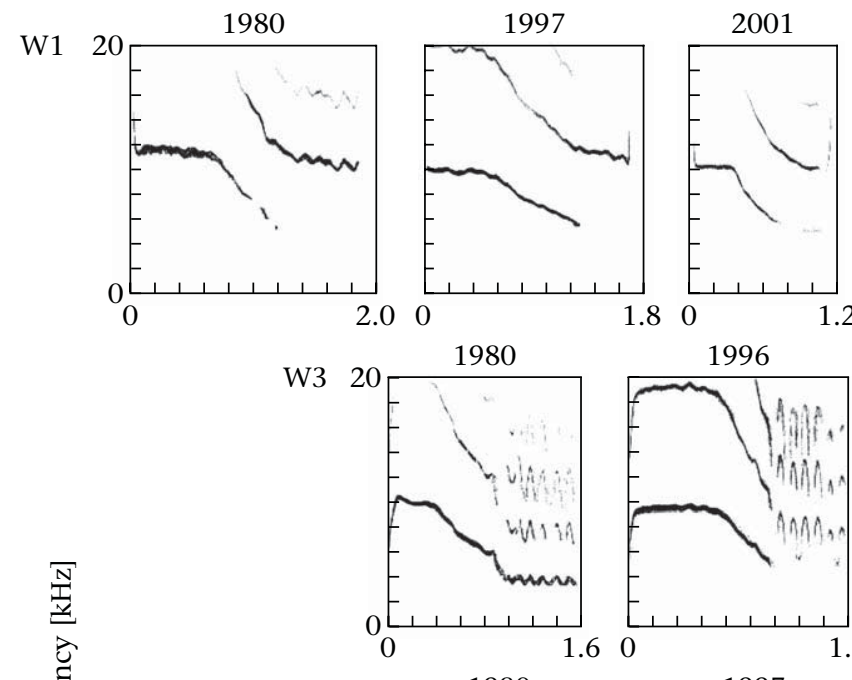

1980
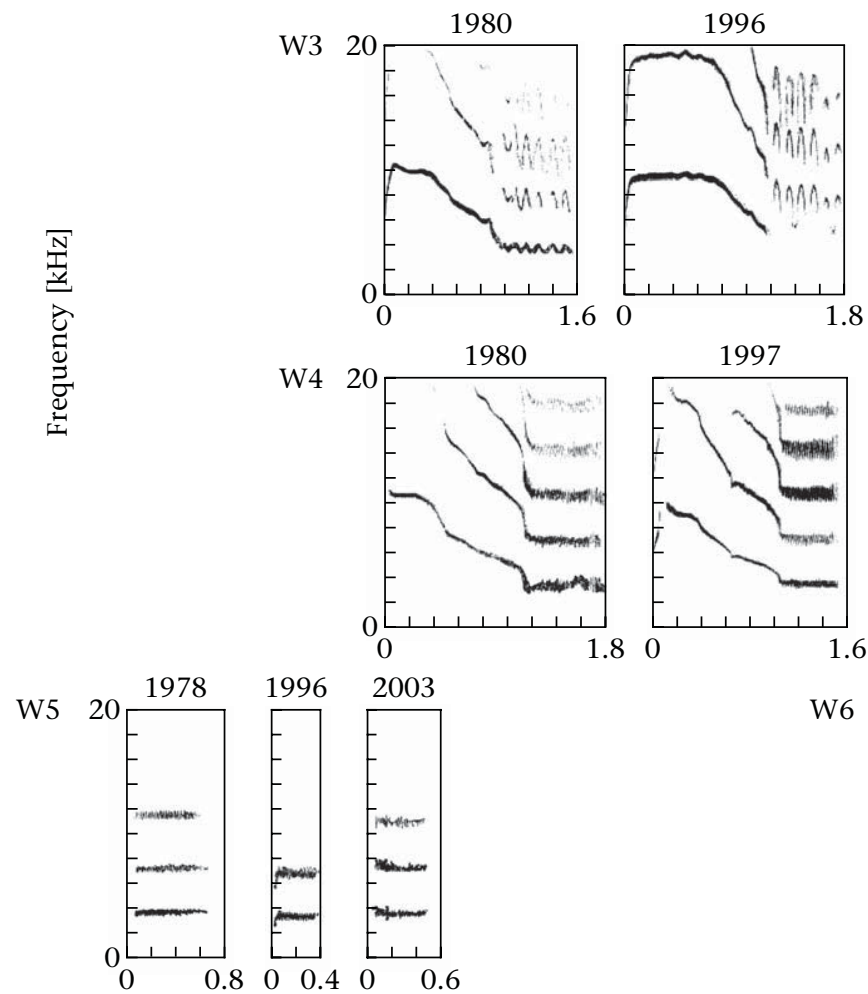

W2
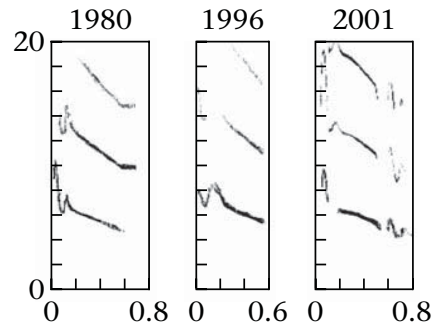

2001
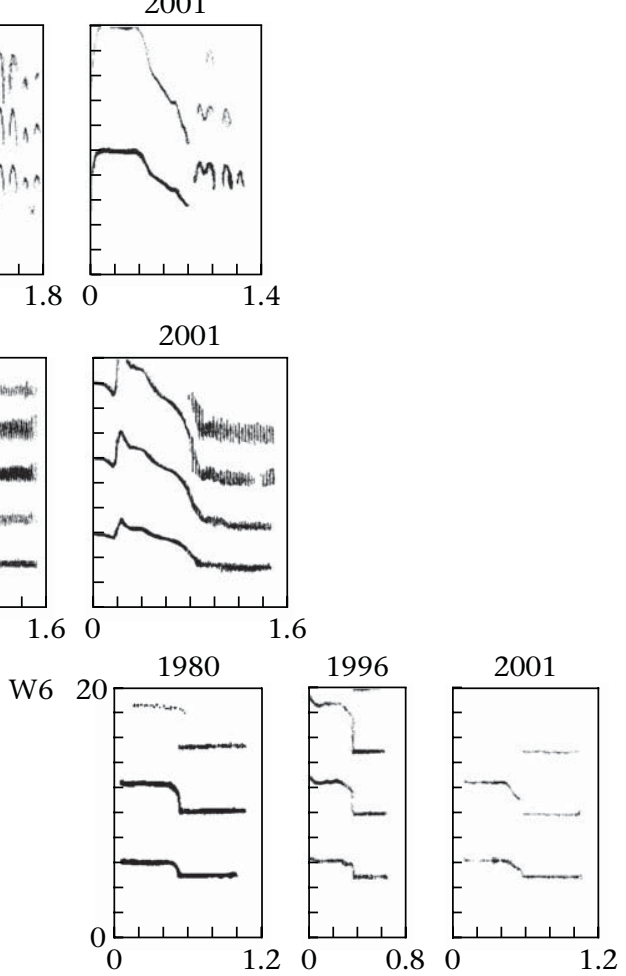

Time [s]

Figure 1. Randomly chosen spectrograms of whistle types W1-W6 from northern resident killer whales recorded in different years (frequency resolution, $\mathrm{DF}=48.8 \mathrm{~Hz}$, time resolution $=20.5 \mathrm{~ms}$, fast Fourier transform size $=1024$ points). 
Table 1. Parameters $(\bar{X} \pm S D)$ of stereotyped whistle types W1-W6 (northern resident killer whales) recorded from 1978 to 2003

\begin{tabular}{|c|c|c|c|c|c|c|c|c|c|}
\hline $\begin{array}{l}\text { Parameter/ } \\
\text { Whistle type }\end{array}$ & $\begin{array}{l}\text { Sample } \\
\text { size }\end{array}$ & $\begin{array}{l}\text { Start } \\
\text { frequency } \\
(\mathrm{kHz})\end{array}$ & $\begin{array}{l}\text { End } \\
\text { frequency } \\
(\mathrm{kHz})\end{array}$ & $\begin{array}{l}\text { Minimum } \\
\text { frequency } \\
\quad(\mathrm{kHz})\end{array}$ & $\begin{array}{l}\text { Maximum } \\
\text { frequency } \\
\quad(\mathrm{kHz})\end{array}$ & $\begin{array}{l}\text { Bandwidth } \\
(\mathrm{kHz})\end{array}$ & $\begin{array}{l}\text { Duration } \\
\text { (s) }\end{array}$ & $\begin{array}{l}\text { Carrier } \\
\text { frequency } \\
\quad(\mathrm{kHz})\end{array}$ & $\begin{array}{l}\text { Frequency } \\
\text { modulations }\end{array}$ \\
\hline W1 & 31 & $12.09 \pm 1.54$ & $5.41 \pm 0.99$ & $4.87 \pm 0.37$ & $12.12 \pm 1.52$ & $7.25 \pm 1.51$ & $1.32 \pm 0.31$ & $10.74 \pm 0.85$ & $8.48 \pm 6.58$ \\
\hline $\mathrm{W} 1_{\mathrm{T}}$ & 39 & $12.64 \pm 1.35$ & $4.38 \pm 1.18$ & $4.07 \pm 1.06$ & $12.64 \pm 1.35$ & $8.58 \pm 1.57$ & $1.45 \pm 0.30$ & $10.47 \pm 1.61$ & $15.49 \pm 7.09$ \\
\hline W2 & 30 & $7.30 \pm 1.34$ & $4.88 \pm 0.61$ & $4.62 \pm 0.57$ & $7.88 \pm 1.51$ & $3.20 \pm 1.50$ & $0.73 \pm 0.22$ & $8.64 \pm 2.97$ & $3.63 \pm 2.59$ \\
\hline $\mathrm{W} 2_{\mathrm{T}}$ & 19 & $8.61 \pm 1.17$ & $5.06 \pm 1.30$ & $4.45 \pm 0.61$ & $9.57 \pm 1.47$ & $5.12 \pm 1.60$ & $0.90 \pm 0.19$ & $7.65 \pm 2.99$ & $6.68 \pm 1.38$ \\
\hline W3 & 63 & $8.82+1.83$ & $5.29+0.98$ & $4.87+0.73$ & $11.06+1.19$ & $6.19+1.25$ & $1.33+0.49$ & $10.33+1.72$ & $6.03+5.47$ \\
\hline $\mathrm{W} 3_{\mathrm{T}}$ & 63 & $8.53 \pm 1.88$ & $4.67 \pm 1.52$ & $4.01 \pm 0.75$ & $10.80 \pm 1.19$ & $6.69 \pm 1.53$ & $1.44 \pm 0.40$ & $10.01 \pm 1.53$ & $12.65 \pm 7.38$ \\
\hline W4 & 15 & $8.80+1.36$ & $4.36+0.69$ & $4.29+0.73$ & $9.93+1.44$ & $5.64+1.34$ & $1.42+0.36$ & $7.86+3.87$ & $3.53+5.55$ \\
\hline W4 $4_{T}$ & 52 & $8.25 \pm 2.26$ & $3.78 \pm 0.38$ & $3.48 \pm 0.33$ & $9.65 \pm 2.12$ & $6.17 \pm 2.05$ & $1.43 \pm 0.37$ & $7.01 \pm 3.98$ & $67.98 \pm 26.86$ \\
\hline W5 & 19 & $3.55 \pm 0.66$ & $3.99 \pm 0.49$ & $3.38 \pm 0.65$ & $4.27 \pm 0.46$ & $0.89 \pm 0.40$ & $0.37 \pm 0.08$ & $4.26 \pm 2.04$ & $50.58 \pm 21.34$ \\
\hline W6 & 33 & $5.83 \pm 0.76$ & $4.87 \pm 0.56$ & $4.74 \pm 0.49$ & $6.17 \pm 0.62$ & $1.43 \pm 0.38$ & $0.86 \pm 0.22$ & $6.98 \pm 3.22$ & $2.15 \pm 1.89$ \\
\hline W6 ${ }_{\mathrm{T}}$ & 26 & $5.28 \pm 0.50$ & $3.65 \pm 0.35$ & $3.36 \pm 0.19$ & $5.50 \pm 0.59$ & $2.13 \pm 0.62$ & $0.98 \pm 0.20$ & $5.40 \pm 3.30$ & $55.31 \pm 13.61$ \\
\hline $\begin{array}{l}\text { Total/ } \\
\text { Means }\end{array}$ & 390 & $8.15 \pm 1.33$ & $4.58 \pm 0.82$ & $4.19 \pm 0.59$ & $9.05 \pm 1.22$ & $4.84 \pm 1.25$ & $1.11 \pm 0.29$ & $8.12 \pm 2.55$ & $21.14 \pm 9.07$ \\
\hline
\end{tabular}

The subscript $\mathrm{T}$ indicates a trill-like ending.

sometimes also included several 'variable' whistles in a stereotyped whistle category. For whistle type W6 only one observer added one 'variable' whistle to this category and in all but one cases all the observers agreed on the classification of the whistle. For whistle types W1, W3 and W4 up to two observers added a maximum of three whistles to the particular category. For whistle types W2 and W5 up to two observers added a maximum of 14 whistles to the particular category.

\section{Stability of Stereotyped Whistles in A-Clan}

The whistle categories showed a high temporal stability from 1978 to 1997. All six whistle types (subcategories

Table 2. Classification of northern resident killer whale whistles by humans

\begin{tabular}{|rrrrrr|}
\hline \multicolumn{7}{|c|}{ Whistle type } \\
\hline W1 & W2 & W3 & W4 & W5 & W6 \\
\hline & & & & \\
$1(4)$ & $6(3)$ & $11(5)$ & $16(5)$ & $20(3)$ & $24(4)$ \\
$2(4)$ & $7(1)$ & $12(5)$ & $17(4)$ & $21(5)$ & $25(5)$ \\
$3(5)$ & $8(4)$ & $13(4)$ & $18(5)$ & $22(5)$ & $26(5)$ \\
$4(2)$ & $9(4)$ & $14(4)$ & $19(4)$ & $23(4)$ & $27(5)$ \\
$5(4)$ & $10(4)$ & $15(4)$ & $29(5)$ & $41(1)$ & $28(5)$ \\
$6(1)$ & $19(1)$ & $43(2)$ & $9(1)$ & $49(1)$ & $58(1)$ \\
$14(1)$ & $37(1)$ & $47(1)$ & $45(1)$ & $55(1)$ & \\
$78(2)$ & $40(1)$ & $76(1)$ & $90(1)$ & $58(1)$ & \\
$88(1)$ & $44(1)$ & & & $67(1)$ & \\
& $64(1)$ & & & $80(1)$ & \\
& $76(2)$ & & & $84(1)$ & \\
& $87(1)$ & & & $90(1)$ & \\
& $96(2)$ & & & $91(1)$ & \\
& & & $95(1)$ & \\
& & & $99(1)$ & \\
\hline
\end{tabular}

Numbers correspond to the identification number of the whistle, while numbers in parentheses indicate how many of the five observers put the corresponding whistle into one type. Identification numbers of stereotyped whistles are in bold. included) were found in both sets of A-clan recordings from 1978 to 1983 and from 1996 to 1997 . The majority of these categories showed no significant change in their parameters over these 13 years ( $t$ test and Mann-Whitney $U$ test: NS in all cases) with the exception of the whistle types $\mathrm{W} 3, \mathrm{~W}^{\mathrm{T}}$ and $\mathrm{W} 6$. $\mathrm{W} 3$ and $\mathrm{W} 3_{\mathrm{T}}$ showed an increase in frequency modulations (W3: $U=397.5, N_{1978-1983}=$ 20, $N_{1996-1997}=17, P=0.024 ; \mathrm{W}_{\mathrm{T}}: t_{46}=-2.612, P=$ 0.012 ), while in W6 the maximum frequency and duration increased (maximum frequency: $U=124$, $N_{1978-1983}=14, \quad N_{1996-1997}=8, \quad P=0.031 ; \quad$ duration: $\left.t_{20}=4.615, P<0.001\right)$.

\section{Group Specificity of Northern Resident Whistles}

We found 81 stereotyped whistles in 'pure' G-clan recordings (recordings where only G-clan whales were in the area during recording). With the exception of the whistle type W5, all whistle types (subcategories included) of the A-clan were found in G-clan recordings as well (Fig. 2, Table 3). However, the sample sizes of four whistle types were too small for the statistical analysis, so that only the remaining six whistle types were analysed. The whistle types $\mathrm{W} 1, \mathrm{~W} 3, \mathrm{~W}_{\mathrm{T}}$ and $\mathrm{W} 6_{\mathrm{T}}$ showed no significant differences in their parameters ( $t$ test and Mann-Whitney $U$ test: NS in all cases). The $\mathrm{W}_{\mathrm{T}}$ version of G-clan had a significantly lower minimum frequency than the version of A-clan $\left(U=692, N_{\text {A-clan }}=49, N_{\text {G-clan }}=14, P<0.001\right)$.

For W6, there were also significant differences in both maximum frequency and bandwidth between the versions of G-clan, A-clan old (1978-1983) and A-clan recent from 1996 to 1997 (maximum frequency, Kruskal-Wallis test: $H_{2}=9.236, \quad P=0.01$; bandwidth, one-way ANOVA: $\left.F_{2,29}=4.40, P=0.021\right)$. Post hoc tests showed that the recent A-clan version had both a higher maximum frequency and higher bandwidth than the G-clan version (maximum frequency, Dunn's method: $P<0.05$; bandwidth, StudentNewman-Keuls method: $P<0.05)$. The biggest difference between W6 types was found in duration: the G-clan 

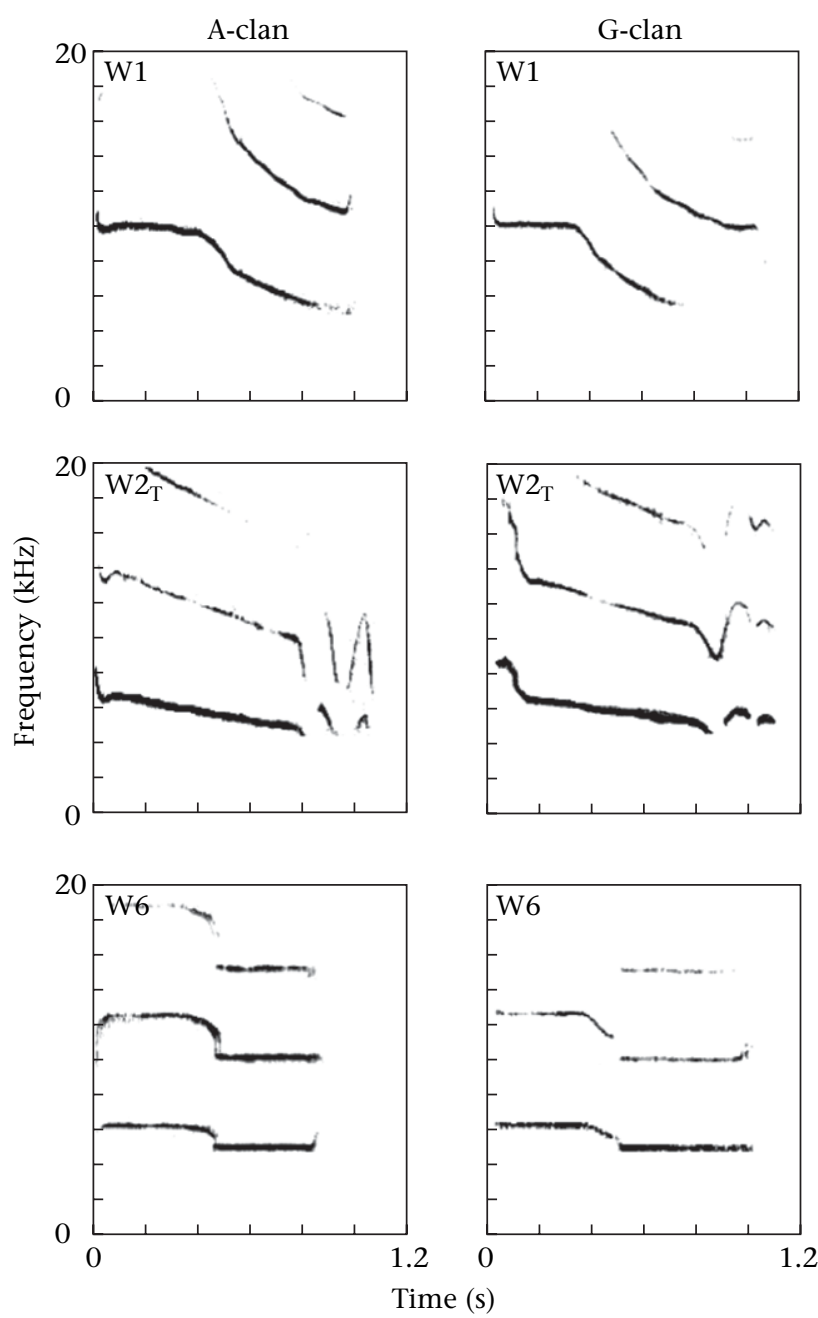

Figure 2. Representative spectrograms of the whistle categories W1, W2 and W6 from A-clan and G-clan (DF $=98 \mathrm{~Hz}$, DT $=10.2 \mathrm{ms,}$ fast Fourier transform size $=512$ points).

version and old A-clan version (1978-1983) were significantly longer than the recent A-clan version from 1996 to 1997 (Fig. 3). This result is even more interesting because all measured G-clan versions that were part of this analysis originated from recordings later than 1990.

The results illustrated in Table 3 suggest that R-clan also uses the same whistle repertoire as A- and G-clans. For an extended analysis of R-clan whistles, we needed recordings for which it was safe to assume that the whistling individuals were of R-clan membership. Unfortunately, there were no such recordings in the database. However, even in recordings of R-clan matrilines mixed with matrilines of other clans, all stereotyped whistles that were found could exclusively be grouped in one of the 11 described stereotyped whistle categories (Table 3). No additional whistle types could be classified.

\section{Stereotyped Whistles of Southern Residents}

We found 152 whistles in the recordings of southern residents from 1979 to 1982 . Of these, 45 whistles (30\%) were stereotyped and could be grouped into four distinct whistle categories (Fig. 4). Hoelzel \& Osborne (1986) mentioned whistle types SW1 and SW2, but labelled them differently. Visually and acoustically, all four whistles were different from the northern resident whistle types. A trait common to three categories (SW1, SW2, SW4) was the socalled 'multiloop', the repetition of a single fragment within a sound category. Again, there was some withincategory variation in some parameters (Table 4 ).

\section{Community Specificity of Stereotyped Whistles}

Although whistles were clearly assigned to the community $(96.60 \%)$, the discriminant function analysis was less successful when whistles were assigned to acoustical clans (78.20\%) and whistle types (65.90\%). If duration was left out of the classification by acoustical clan and by community, the success rate did decrease slightly (clans: 71.10\%; community: $89.50 \%$ ). The discriminant function analysis for optimal separation of whistle types clearly differentiated three groups of whistles. One group consisted of the highly frequency-modulated whistle types $\mathrm{W} 4_{\mathrm{T}}$, W5 and $\mathrm{W} 6_{\mathrm{T}}$, another group comprised the southern resident whistles SW1, SW2 and SW4, and the rest were placed into a third group (Fig. 5). However, the discriminant function analysis for optimal separation of acoustical clans differentiated only two groups (Fig. 6). The two northern resident clans $A$ and $G$ were placed into one group and the whistles of the southern resident clan $\mathrm{J}$ were placed into a separate group (Fig. 6). The most important variables in discrimination by whistle type were maximum frequency, frequency modulations, bandwidth and duration. For the other two discrimination analyses the important variables were duration, bandwidth, maximum frequency and start frequency (Table 5).

\section{DISCUSSION}

\section{Stereotyped Whistles as Discrete Signals}

Stereotyped whistles of resident killer whales off Vancouver Island clearly represent discrete classes. Our classification of sounds based on visual inspection of spectrogram contours is a common technique that has been used in various other studies on delphinid whistles and burst-pulses (Ford \& Fisher 1983; Hoelzel \& Osborne 1986; Ford 1989, 1991; Caldwell et al. 1990; Janik 1999). We also showed that additional observers agreed with our initial classification. However, some whistle types were classified by the observers more rigidly than others. For example in some cases (e.g. W2 and W5) several 'variable whistles' were added to the 'stereotyped' ones (Table 2). This might be explained by methodology. The spectrographic prints used in the experiment were normalized for duration. Both whistle types are comparably short and it is therefore possible that important distinctive features, for example fine-scale variations in frequency modulation, were not visible and hence were missed by the observers. None the less, interobserver reliability was very high. 
Table 3. All 1739 stereotyped whistles from northern resident killer whale recordings listed by matriline (1978-2003)

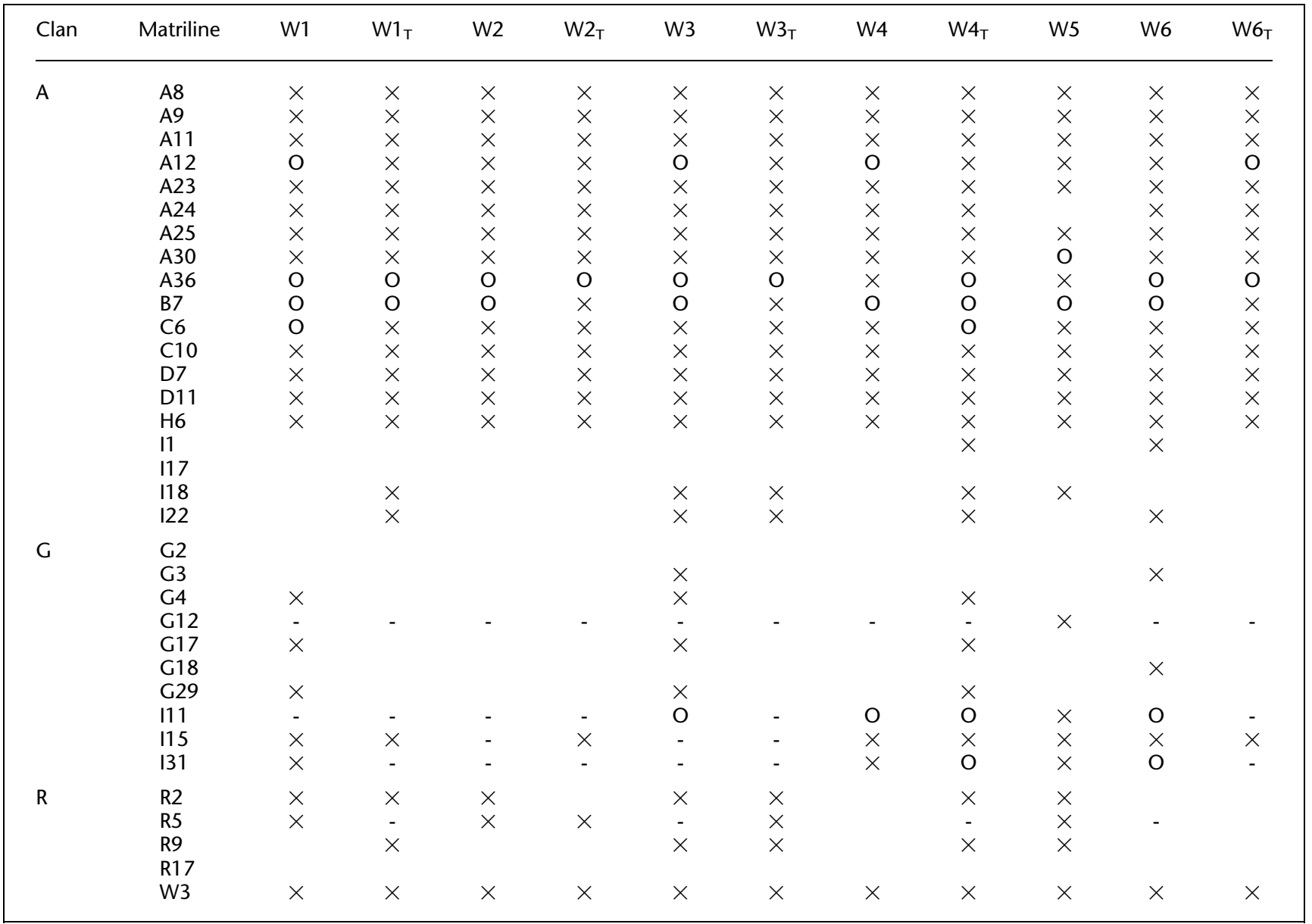

$X$ : whistle type found in recordings of matriline mixed with other matrilines; -: whistle type found in recordings of matriline with absence of Aclan matrilines; O: whistle type found in recordings of solitary matriline.

Other studies have also shown that subjectivity in classification can be overcome by using additional observers, and that the human method is at least as reliable if not superior to automated computer-based ones (Janik 1999;

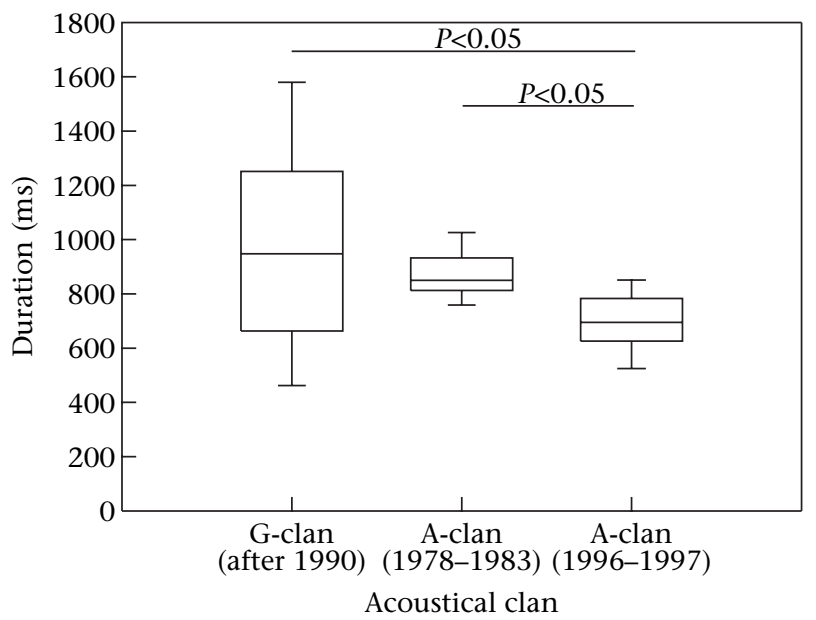

Figure 3. Whistle duration of the whistle type $\mathrm{W} 6$ in recordings from G-clan and A-clan (Kruskal-Wallis test: $H_{2}=9.720, N_{\text {G-clan }}=10$, $N_{78-83}=14, N_{96-97}=8, P=0.008$; Dunn's method: $\left.P<0.05\right)$.
Deecke et al. 1999; McCowan \& Reiss 2001; Yurk et al. 2002; Watwood et al. 2004). The within-category variability of certain whistle parameters does not contradict their definition as distinct classes, because most discrete mammalian sounds, including signature whistles of bottlenose dolphins, show within-category variation (Theberge \& Falls 1967; Marler 1973; Waser 1975; Gautier \& Gautier 1977; Byrne 1981, 1982; Ford 1989; Caldwell et al. 1990; Janik et al. 1994; Tyack \& Sayigh 1997).

\section{Whistle Stability}

The whistle types are not only discrete, but also stable in spectrographic contour over extended periods. However, there was some fine-scale variation: whistle types $\mathrm{W} 3, \mathrm{~W} 3_{\mathrm{T}}$ and W6 changed in some of their parameters between 1978 and 1997, most notably the number of frequency modulations. Furthermore, the whistle W6 showed a significant increase in maximum frequency and a significant decrease in duration over the same period. It is possible that the role of stereotyped whistles during social interactions is so important that it would be biologically unfavourable to change them significantly. If this assumption is correct, then the whistle W6 might be a signal that is not as specific in its 

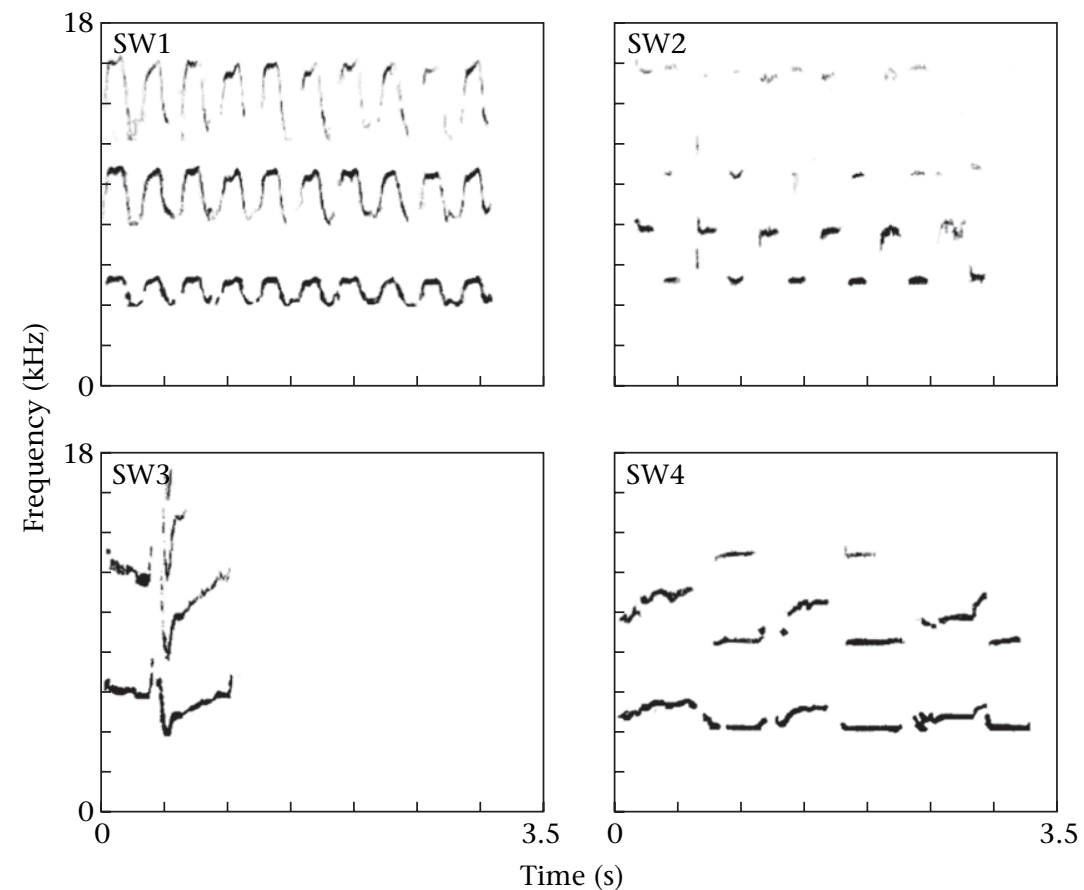

Figure 4. Representative spectrograms of the whistle types SW1-SW4 from southern resident killer whales (DF $=98 \mathrm{~Hz}, \mathrm{DT}=10.2 \mathrm{~ms}$, fast Fourier transform size $=512$ points).

function as the other whistle types and therefore is exposed to greater pressure for parameter change than other whistle categories. However, the G-clan version of the whistle W6 did not change accordingly but rather remained stable. Deecke et al. (2000) found that discrete calls of northern resident killer whales also undergo minor structural change over time, whereas the overall contour of the call remains the same. Gradual changes in whistle structure might indicate that whistles are learned rather than genetically fixed as has been proposed for discrete calls (Deecke et al. 2000).

\section{Whistle Traditions in Resident Killer Whales}

Another major finding of our study is that killer whales that show no overlap in call repertoire use essentially the same set of stereotyped whistles. With the exception of one whistle type (W5), all stereotyped whistles of the A-clan were found in the G-clan matrilines as well. Because W5 is used rarely even in A-clan, it is likely to be part of the G-clan repertoire but was missed by chance. At this point we cannot rule out that R-clan whales use different stereotyped whistles. However, the results illustrated in Table 4 suggest that R-clan also uses the same whistle repertoire as A- and G-clans. In recordings of R-clan matrilines mixed with matrilines of other clans, all stereotyped whistles that were found could exclusively be grouped in one of the six stereotyped whistle categories (subcategories included). It is therefore likely that the stereotyped whistles described in this study are used not only by A- and G-clans but also by R-clan whales. The only statistically significant parameter difference between clans was found in the whistle types $\mathrm{W} 3_{\mathrm{T}}$ and $\mathrm{W} 6$. The G-clan version of $\mathrm{W} 3_{\mathrm{T}}$ had a significantly lower minimum frequency than the A-clan version and the G-clan version of W6 had a significantly lower maximum frequency and bandwidth than the A-clan version from 1996 to 1997 and was also shorter in duration. No differences were found between the old A-clan version from 1978 to 1983 and that of G-clan.

The stereotyped whistles of southern residents between 1978 and 1982, on the other hand, clearly differed from those of northern residents recorded during the same

Table 4. Parameters $(\bar{X} \pm S D)$ of stereotyped whistle types SW1-SW4 (southern resident killer whales) recorded from 1979 to 1982

\begin{tabular}{|lccccccccc|}
\hline $\begin{array}{l}\text { Parameter/ } \\
\text { Whistle } \\
\text { type }\end{array}$ & $\begin{array}{c}\text { Sample } \\
\text { size }\end{array}$ & $\begin{array}{c}\text { Start } \\
\text { frequency } \\
(\mathrm{kHz})\end{array}$ & $\begin{array}{c}\text { End } \\
\text { frequency } \\
(\mathrm{kHz})\end{array}$ & $\begin{array}{c}\text { Minimum } \\
\text { frequency } \\
(\mathrm{kHz})\end{array}$ & $\begin{array}{c}\text { Maximum } \\
\text { frequency } \\
(\mathrm{kHz})\end{array}$ & $\begin{array}{c}\text { Bandwidth } \\
(\mathrm{kHz})\end{array}$ & Duration (s) & $\begin{array}{c}\text { Carrier } \\
\text { frequency } \\
(\mathrm{kHz})\end{array}$ & $\begin{array}{c}\text { Frequency } \\
\text { modulations }\end{array}$ \\
\hline SW1 & 17 & $5.43 \pm 0.70$ & $4.88 \pm 0.50$ & $4.35 \pm 0.52$ & $6.02 \pm 0.37$ & $1.67 \pm 0.55$ & $6.23 \pm 2.78$ & $5.50 \pm 0.22$ & $45.24 \pm 19.71$ \\
SW2 & 14 & $6.39 \pm 1.54$ & $5.86 \pm 1.04$ & $4.95 \pm 0.51$ & $7.76 \pm 1.31$ & $2.81 \pm 0.92$ & $3.67 \pm 2.15$ & $6.11 \pm 1.83$ & $9.79 \pm 6.48$ \\
SW3 & 8 & $6.42 \pm 0.49$ & $5.82 \pm 0.23$ & $4.24 \pm 0.32$ & $7.33 \pm 1.34$ & $3.09 \pm 1.22$ & $1.00 \pm 0.18$ & $5.90 \pm 0.19$ & $5.88 \pm 2.10$ \\
SW4 & 6 & $4.49 \pm 0.10$ & $4.84 \pm 0.45$ & $4.21 \pm 0.09$ & $6.08 \pm 0.32$ & $1.86 \pm 0.36$ & $5.96 \pm 1.88$ & $7.15 \pm 3.48$ & $42.17 \pm 14.25$ \\
Total/Means & 45 & $5.81 \pm 0.71$ & $5.35 \pm 0.56$ & $4.44 \pm 0.36$ & $6.80 \pm 0.84$ & $2.36 \pm 0.76$ & $4.21 \pm 1.75$ & $6.17 \pm 1.43$ & $25.77 \pm 10.64$ \\
\hline
\end{tabular}




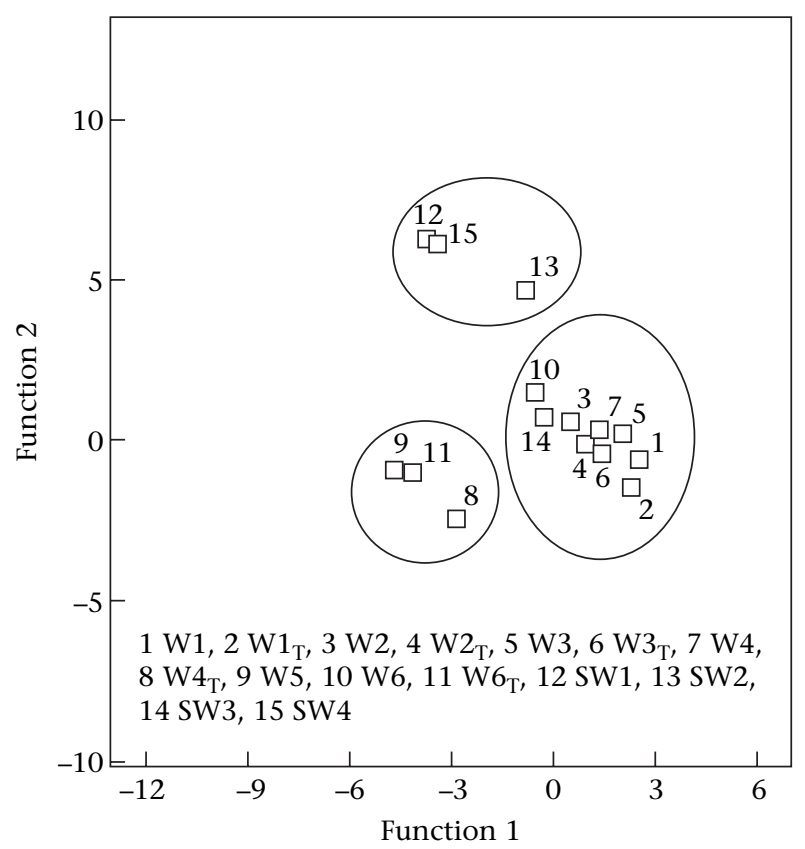

Figure 5. Results for the discriminant function analysis for optimal separation of whistle types. Each square represents the centroid of discriminant function scores of all measured whistles of each whistle type. Discriminant function 1 correlates with maximum frequency and discriminant function 2 with frequency modulations.

period. Northern and southern residents, despite considerable overlap in their home ranges, are socially isolated, which may have led to differing whistle repertoires. An analogous situation exists in many songbird species

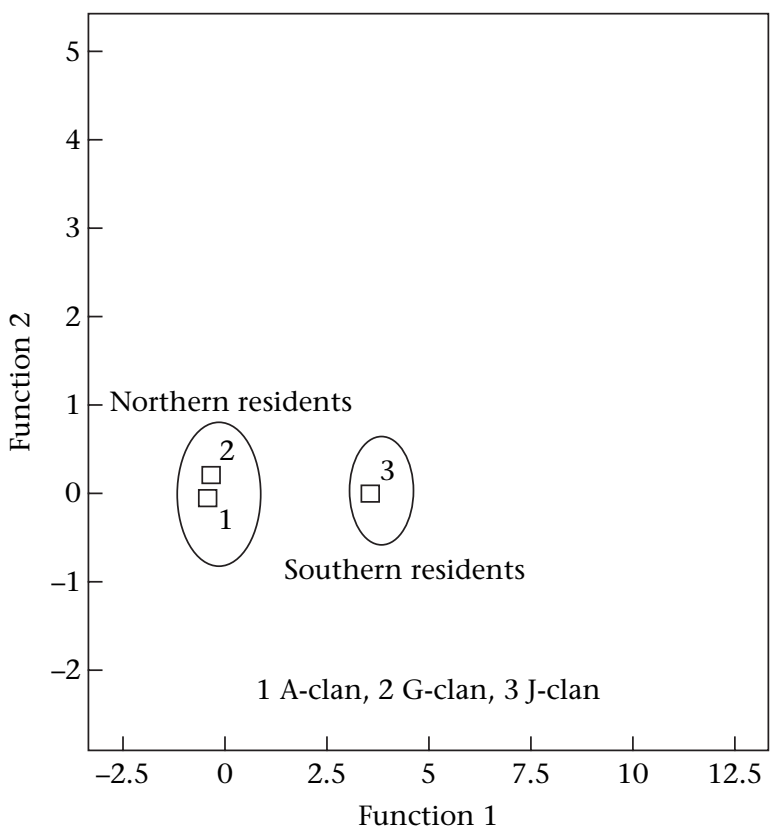

Figure 6. Results for the discriminant function analysis for optimal separation of acoustical clans. Each square represents the centroid of discriminant function scores of all measured whistles of each acoustical clan. Discriminant function 1 correlates with whistle duration and discriminant function 2 with bandwidth.
Table 5. Equality tests of group means for different whistle parameters and different groupings

\begin{tabular}{|c|c|c|c|}
\hline Whistle parameter & Wilk's lambda & $F$ & $P$ \\
\hline \multicolumn{4}{|l|}{ Whistle types } \\
\hline Start frequency & 0.291 & 68.853 & 0.001 \\
\hline End frequency & 0.702 & 12.013 & 0.001 \\
\hline Minimum frequency & 0.567 & 21.555 & 0.001 \\
\hline Maximum frequency & 0.220 & 100.433 & 0.001 \\
\hline Bandwidth & 0.246 & 86.752 & 0.001 \\
\hline Whistle duration & 0.276 & 73.996 & 0.001 \\
\hline Carrier frequency & 0.609 & 18.127 & 0.001 \\
\hline Frequency modulations & 0.222 & 98.906 & 0.001 \\
\hline \multicolumn{4}{|l|}{ Acoustical clans } \\
\hline Start frequency & 0.916 & 19.933 & 0.001 \\
\hline End frequency & 0.953 & 10.684 & 0.001 \\
\hline Minimum frequency & 0.976 & 5.364 & 0.005 \\
\hline Maximum frequency & 0.907 & 22.322 & 0.001 \\
\hline Bandwidth & 0.887 & 27.737 & 0.001 \\
\hline Whistle duration & 0.513 & 207.815 & 0.001 \\
\hline Carrier frequency & 0.935 & 15.094 & 0.001 \\
\hline Frequency modulations & 0.993 & 1.450 & 0.236 \\
\hline \multicolumn{4}{|l|}{ Resident communities } \\
\hline Start frequency & 0.918 & 39.103 & 0.001 \\
\hline End frequency & 0.961 & 17.697 & 0.001 \\
\hline Minimum frequency & 0.990 & 4.363 & 0.037 \\
\hline Maximum frequency & 0.908 & 44.254 & 0.001 \\
\hline Bandwidth & 0.887 & 55.600 & 0.001 \\
\hline Whistle duration & 0.513 & 416.458 & 0.001 \\
\hline Carrier frequency & 0.938 & 28.754 & 0.001 \\
\hline Frequency modulations & 0.996 & 1.881 & 0.171 \\
\hline
\end{tabular}

A small Wilk's lambda and a high $F$ statistic indicate good discriminating ability.

which are geographically and socially isolated. For example, in the cardinal, Cardinalis cardinalis, or the chaffinch, Fringilla coelebs, neighbouring individuals tend to sing similar songs, whereas the songs of individuals from different locations show clear differences (Marler \& Tamura 1962; reviewed in Slater 1989, 2003). The same can be found in the songs of the humpback whale, Megaptera novaeangliae. Males of each breeding ground sing more or less the same song, whereas songs from different breeding grounds show distinct differences (Cerchio et al. 2001).

For two reasons, we think that major changes in the whistle repertoires of southern residents in the years after 1982 are unlikely. First, the stereotyped whistles of the northern residents proved to be highly stable structures that changed little during more than 13 years. Second, Hoelzel \& Osborne (1986) described four different 'whistle-calls' in southern resident killer whales that were stable over at least 3 summers. We can therefore assume that the whistle types described here are representative of the current stereotyped whistles of the southern resident community.

\section{Possible Transmission Paths of Stereotyped Whistles}

The question arises whether the community-specific repertoire of stereotyped whistles is transmitted genetically across generations or whether it is learned. Also, if it is 
learned, then how does learning take place? Vocal learning has been proven to be the major factor behind acoustical development in delphinids (reviewed in Janik \& Slater 1997, 2000). Tyack (1986) showed that captive bottlenose dolphins imitated each other's signature whistles, and Caldwell et al. (1990) found that bottlenose dolphin infants produce nonstereotyped whistles at birth and gradually develop a signature as they mature. For killer whales, vocal learning is also likely. Bain (1986) and Ford (1991) observed captive killer whales that were caught in different locations and had different vocal traditions imitating the calls of their pool mates when held together in captivity. Vocal learning is the most probable mechanism behind vocal mimicry (Ford 1991; Janik \& Slater 1997) as well as horizontal transmission of discrete calls in wild killer whales (Deecke et al. 2000). We believe our results provide evidence that stereotyped whistles are also learned. First, differences in the sound repertoires between northern and southern residents are more likely to appear if vocal learning rather than genetic inheritance plays a major role in the development of vocalizations. Second, the fine-scale changes in some whistle types over time support the hypothesis of whistle learning in killer whales. For example, the occurrence of frequency modulations in W3 is most likely to be the result of innovation or cultural drift (Mundinger 1980; Lynch 1996; Payne 1996; Deecke et al. 2000; Janik \& Slater 2000, see below). Finally, mating in northern residents takes place predominantly between members of different clans (Barrett-Lennard 2000). If the whistle repertoire were genetically coded, one would expect to find a mix of old and new versions of the W6 whistle in both clans, which would probably not lead to significant differences between the clans, as was the case in the present study.

Social sounds might change over time because of cultural drift where incorrect copying may lead to the evolution of new versions (Lemon 1975; Ford 1991; Lynch 1996; Deecke et al. 2000). For example, cultural drift has been described for the spreading of new syllables in the songs of honeyeaters, Meliphaga virescens (Baker et al. 2001), and for structural changes of discrete calls in resident killer whales (Deecke et al. 2000). The finding that the whistle type W6 changed in the A-clan over time might be explained by this phenomenon. Another possibility is innovation, whereby an individual creatively changes the structure of an established sound feature (Ford 1991; Payne 1996; Kroodsma et al. 1997, 1999; Janik \& Slater 2000; Baker et al. 2001; Nowicki et al. 2001). It is impossible to know whether the change observed in W6 was caused by innovation or incorrect learning. In this context it is important to know how often the process of whistle copying can take place throughout the life of a killer whale. Males have an average life expectancy of 30 years and females 50 years (Olesiuk et al. 1990). Therefore, a substantial proportion of the northern resident community from 1978 was still alive in 1996-1997. If the process of whistle copying from conspecifics takes place only in calves, we would expect to find the altered version of W6 only sporadically in recent recordings, because many adult animals from 1978 were still alive. In any case, the altered version of W6 would not be expected to appear often enough to lead to a significant parameter change in an A-clan population of about 110 animals. Studies on other animals, for example black-capped chickadees, Parus atricapillus, have also shown that vocal learning might take place in both juveniles and adult animals (Nowicki 1989). Thus, it is more likely that the process of whistle learning takes place throughout the life of a killer whale during socializing, when individuals from different clans meet. In a variety of species the degree of vocal resemblance depends on the amount of social interactions (e.g. black-capped chickadees: Nowicki 1989; greater spear-nosed bats, Phyllostomus hastatus: Boughman 1998; bottlenose dolphins: Smolker \& Pepper 1999; Watwood et al. 2004). If this is the case, then slight differences in the whistle repertoires (e.g. W6) between certain parts of the population may indicate differences in the rate of interactions and associations between different matrilines.

\section{Possible Function of Stereotyped Whistles}

At this stage it is easier to conclude what functions are not served by stereotyped whistles than to ascribe their specific role in communication among killer whales. In a variety of other delphinids stereotyped whistles serve as individual-specific signatures (Caldwell \& Caldwell 1971, 1977; Caldwell et al. 1973; Janik \& Slater 1998; Janik 1999; Herzing 2000; Tyack \& Clark 2000; reviewed in Caldwell et al. 1990; Tyack 1998). The different social structure of resident killer whales compared with other delphinids, for example the bottlenose dolphin, makes the development of signature whistles unlikely. In general, bottlenose dolphins live in fission-fusion societies (Smolker et al. 1993) where individuals form highly stable associations with some individuals as well as open formations with others. In contrast, resident killer whales form stable matrilineal groups with no dispersal by either sex (Bigg et al. 1990). In killer whale societies, group identity encoded in stereotyped signals is probably more important than the individual identity of the group members. Another argument against stereotyped whistles being individual signatures is their context specificity. If whistles serve primarily as individualized cohesion signals, we would expect signature whistles to be most common in long-range communication. For example, in bottlenose dolphins and spotted dolphins, Stenella frontalis, signature whistles are produced predominantly when individuals are either voluntarily or forcibly separated, or during reunions of mother and calf pairs (Smolker et al. 1993; Janik \& Slater 1998; Tyack 1998; Herzing 2000; Cook et al. 2004). However, Ford (1989) and Thomsen et al. (2002) showed that the opposite is true in northern resident killer whales.

Our results provide further evidence against signature whistles in killer whales. First, whistle types are not exclusively individually specific since the same whistle types were recorded from individuals of different matrilines (Table 3). Second, if killer whale whistles are individual signatures, we would also expect to identify a greater number of whistle types since we analysed large data sets of several matrilines with many more than six animals present during the recordings. 
What then is the biological role of stereotypy in whistles of wild killer whales? In resident killer whales in southern Alaska one discrete and group-specific vocalization (AKS05) is clearly tonal instead of pulsed (Yurk et al. 2002). However, this particular whistle was recorded in various behavioural situations, including foraging and travelling (Yurk et al. 2002). For southern residents Hoelzel \& Osborne (1986) provided only limited information on the behavioural context of stereotyped whistles. Our observations indicate that in this population, unlike northern residents, whistles are prevalent in long-range communication, for example during foraging and slow travelling. It is therefore likely that some of the above mentioned whistle types serve the same function as certain discrete calls: maintaining contact and coordinating group movements over long distances (Ford 1989; Miller \& Bain 2000; Miller 2002; Miller et al. 2004). On the other hand, Ford (1991) noted repetitive series of whistles in southern residents, which were emitted mostly during socializing activities. These whistles were short (100-400 ms), constant-pitch sounds repeated at rates of $1-8 \mathrm{~s}$ for periods of up to $30 \mathrm{~s}$.

In northern resident killer whales, stereotyped whistles are evidently used for close-range signalling. Many behaviours that take place during close-range interactions are affiliative in nature (Ford 1989). Shared stereotyped whistles might provide a community-level means of recognition that facilitates association and affiliation of members of different clans, which otherwise use distinct signals. It is possible that temporal emission patterns of stereotyped whistles are important here. We constantly noted repetitive series of stereotyped whistles that occurred during socializing and social travelling very similar to the sequences described by Ford (1991). Thus, sequences might be of great importance in coordinating and maintaining interactions at close range. Further studies using hydrophone arrays to reveal sound-source locations would help shed light on the role of these sequences in the acoustic communication system of killer whales.

\section{Acknowledgments}

We thank Jim Borrowman and Bill and Donna Mackay for their great support for this study. Thanks to Robert Butler, Wayne Garton, Rolf Hicker, Brian Sylvester, Dave Tyre and Steve Wischniowski for their help in the field. Dave Briggs, Helena Symonds, Paul Spong, Rob Williams and Anna Spong provided important information on whale locations. R.R. and F.T. thank Dierk Franck, Jakob Parzefall, Cord Crasselt, Ralf Wanker, Massoud Yasseri and Ingo Schlupp for their help during the analysis at Hamburg University. Volker Deecke generously supplied additional sound recordings from 1999 to 2001. We thank Christina Jakisch, Simone Hinzpeter, Stephanie Wanker-Stempell, Rouven Schmidt and Stefan Froschauer for their help in whistle classification. This study was partly funded by scholarships from the Deutscher Akademischer Austauschdienst (DAAD), the University of Hamburg (Graduiertenstipendium) and the Hansische Universitätsstiftung.

\section{References}

Bain, D. E. 1986. Acoustic behaviour of Orcinus: sequences, periodicity, behavioral correlates and an automated technique for call classification. In: Behavioral Biology of Killer Whales (Ed. by B. C. Kirkevold \& J. S. Lockard), pp. 335-371. New York: A.R. Liss.

Baker, M. C., Baker, E. M. \& Baker, M. S. A. 2001. Island and island-like effects on vocal repertoire of singing honeyeaters. Animal Behaviour, 62, 767-774.

Barrett-Lennard, L.G. 2000. Population structure and mating patterns of killer whales, Orcinus orca, as revealed by DNA analysis. Ph.D. thesis, University of British Columbia, Vancouver.

Barrett-Lennard, L. G., Ford, J. K. B. \& Heise, K. A. 1996. The mixed blessing of echolocation: differences in sonar use by fish-eating and mammal-eating killer whales. Animal Behaviour, 51, 553-565.

Bigg, M. A., Olesiuk, P. F., Ellis, G. M., Ford, J. K. B. \& Balcomb, K. C., III. 1990. Social organization and genealogy of resident killer whales (Orcinus orca) in the coastal waters of British Columbia and Washington State. Reports of the International Whaling Commission, 12, 383-405.

Boughman, J. W. 1998. Vocal learning by greater spear-nosed bats. Proceedings of the Royal Society of London, Series B, 265, 227-233.

Byrne, R. W. 1981. Distance vocalisations of Guinea baboons (Papio papio) in Senegal: an analysis of function. Behaviour, 78, 283-312.

Byrne, R. W. 1982. Primate vocalisations: structural and functional approaches to understanding. Behaviour, 80, 241-258.

Caldwell, M. C. \& Caldwell, D. K. 1971. Statistical evidence for individual signature whistles in Pacific white-sided dolphins, Lagenorhynchus obliquidens. Cetology, 3, 1-9.

Caldwell, M. C. \& Caldwell, D. K. 1977. Cetaceans. In: How Animals Communicate (Ed. by T. A. Sebeok), pp. 794-808. Bloomington: Indiana University Press.

Caldwell, M. C., Caldwell, D. K. \& Miller, J. F. 1973. Statistical evidence for individual signature whistles in the spotted dolphin (Stenella plagiodon). Cetology, 16, 1-21.

Caldwell, M. C., Caldwell, D. K. \& Tyack, P. L. 1990. Review of the signature-whistle hypothesis for the Atlantic bottlenose dolphin. In: The Bottlenose Dolphin (Ed. by S. Leatherwood \& R. R. Reeves), pp. 199-234. San Diego: Academic Press.

Cavalli-Sforza, L. L. \& Feldman, M. W. 1981. Cultural Transmission and Evolution: a Quantitative Approach. Princeton, New Jersey: Princeton University Press.

Cerchio, S., Jacobsen, J. K. \& Norris, T. F. 2001. Temporal and geographical variation in songs of humpback whales, Megaptera novaeangliae: synchronous change in Hawaiian and Mexican breeding assemblages. Animal Behaviour, 62, 313-329.

Cook, M. L. H., Sayigh, L. S., Blum, J. E. \& Well, R. S. 2004. Signature-whistle production in undisturbed free-ranging bottlenose dolphins (Tursiops truncatus). Proceedings of the Royal Society of London, Series B, 271, 1043-1049.

Deecke, V. B., Ford, J. K. B. \& Spong, P. 1999. Quantifying complex patterns of bioacoustic variation: use of a neural network to compare killer whale (Orcinus orca) dialects. Journal of the Acoustical Society of America, 105, 2499-2507.

Deecke, V. B., Ford, J. K. B. \& Spong, P. 2000. Dialect change in resident killer whales: implications for vocal learning and cultural transmission. Animal Behaviour, 60, 629-638.

Ford, J. K. B. 1989. Acoustic behaviour of resident killer whales (Orcinus orca) off Vancouver Island, British Columbia. Canadian Journal of Zoology, 67, 727-745.

Ford, J. K. B. 1991. Vocal traditions among resident killer whales (Orcinus orca) in coastal waters of British Columbia. Canadian Journal of Zoology, 69, 1454-1483.

Ford, J. K. B. \& Fisher, H. D. 1983. Group-specific dialects of killer whales (Orcinus orca) in British Columbia. In: Communication and 
Behavior of Whales (Ed. by R. Payne), pp. 129-161. Boulder, Colorado: Westview Press.

Ford, J. K. B., Ellis, G. E. \& Balcomb, K. C. 1994. Killer Whales. Vancouver: University of British Columbia Press.

Ford, J. K. B., Ellis, G. E. \& Balcomb, K. C., III. 2000. Killer Whales. 2nd edn. Vancouver: University of British Columbia Press.

Gautier, J.-P. \& Gautier, A. 1977. Communication in old world monkeys. In: How Animals Communicate (Ed. by T. A. Sebeok), pp. 890-964. Bloomington: Indiana University Press.

Herzing, D. 2000. Acoustics and social behavior of wild dolphins: implications for a sound society. In: Hearing by Whales and Dolphins (Ed. by W. W. L. Au, A. N. Popper \& R. R. Fay), pp. 225273. New York: Springer Verlag.

Hoelzel, A. R. \& Osborne, R. W. 1986. Killer whale call characteristics: implications for cooperative foraging strategies. In: Behavioral Biology of Killer Whales (Ed. by B. C. Kirkevolt \& J. S. Lockard), pp. 373-403. New York: A.R. Liss.

Janik, V. M. 1999. Pitfalls in the categorization of behaviour: a comparison of dolphin whistle classification methods. Animal Behaviour, 57, 133-143.

Janik, V. M. \& Slater, P. J. B. 1997. Vocal learning in mammals. Advances in the Study of Behaviour, 26, 59-99.

Janik, V. M. \& Slater, P. J. B. 1998. Context-specific use suggests that bottlenose dolphin signature whistles are cohesion calls. Animal Behaviour, 56, 829-838.

Janik, V. M. \& Slater, P. J. B. 2000. The different roles of social learning in vocal communication. Animal Behaviour, 60, 1-11.

Janik, V. M., Dehnhardt, G. \& Todt, D. 1994. Signature whistle variations in a bottlenose dolphin, Tursiops truncatus. Behavioral Ecology and Sociobiology, 35, 243-248.

Kroodsma, D. E., Houlihan, P. W., Fallon, P. A. \& Wells, J. A. 1997. Song development by grey catbirds. Animal Behaviour, 54, 457-464.

Kroodsma, D. E., Liu, W.-C., Goodwin, E. \& Bedell, P. A. 1999. The ecology of song improvisation as illustrated by North American sedge wrens. Auk, 116, 373-386.

Lemon, R. E. 1975. How birds develop song dialects. Condor, 77, 385-406.

Lynch, A. 1996. Population memetics of bird song. In: Ecology and Evolution of Acoustic Communication in Birds (Ed. by D. E. Kroodsma \& E. H. Miller), pp. 181-197. Ithaca: Comstock.

McCowan, B. \& Reiss, D. 2001. The fallacy of 'signature whistles' in bottlenose dolphins: a comparative perspective of 'signature information' in animal vocalizations. Animal Behaviour, 62, 1151-1162.

Marler, P. 1973. A comparison of vocalizations of red-tailed monkeys and blue monkeys, Cercopithecus ascanius and C. mitis, in Uganda. Zeitschrift für Tierpsychologie, 33, 223-247.

Marler, P. \& Tamura, M. 1962. Song "dialects" in three populations of white-crowned sparrows. Condor, 64, 368-377.

Miller, P. J. O. 2002. Mixed-directionality of killer whale stereotyped calls: a direction of movement cue? Behavioral Ecology and Sociobiology, 52, 262-270.

Miller, P. J. O. \& Bain, D. E. 2000. Within-pod variation in killer whale calls. Animal Behaviour, 60, 617-628.

Miller, P. J. O., Shapiro, A. D., Tyack, P. L. \& Solow, A. R. 2004. Call-type matching in vocal exchanges of free-ranging resident killer whales, Orcinus orca. Animal Behaviour, 67, 1099-1107.

Mundinger, P. C. 1980. Animal cultures and a general theory of cultural evolution. Ethology and Sociobiology, 1, 183-223.

Nowicki, S. 1989. Vocal plasticity in captive black-capped chickadees: the acoustic basis and rate of call convergence. Animal Behaviour, 37, 64-73.

Nowicki, S., Searcy, W. A., Hughes, M. \& Podos, J. 2001. The evolution of bird song: male and female response to song innovation in swamp sparrows. Animal Behaviour, 62, 1189-1195.
Olesiuk, P. F., Bigg, M. A. \& Ellis, G. E. 1990. Life history and population dynamics of resident killer whales (Orcinus orca) in the coastal waters of British Columbia and Washington State. Reports of the International Whaling Commission, 12, 209-243.

Payne, R. B. 1996. Song traditions in indigo buntings: origin, improvisation, dispersal, and extinction in cultural evolution. In: Ecology and Evolution of Acoustic Communication in Birds (Ed. by D. E. Kroodsma \& E. H. Miller), pp. 198-220. Ithaca: Cornell University Press.

Rendell, L. \& Whitehead, H. 2004. Do sperm whales share coda vocalizations? Insights into coda usage from acoustic size measurement. Animal Behaviour, 67, 865-874.

Sayigh, L. S., Tyack, P. L., Wells, R. S. \& Scott, M. D. 1990. Signature whistles of free-ranging bottlenose dolphins Tursiops truncatus: stability and mother-offspring comparisons. Behavioral Ecology and Sociobiology, 26, 247-260.

Siegel, S. \& Castellan, N. J., Jr. 1988. Nonparametric Statistics for the Behavioral Sciences. 2nd edn. New York: McGraw-Hill.

Slater, P. J. B. 1989. Bird song learning: causes and consequences. Ethology Ecology and Evolution, 1, 19-46.

Slater, P. J. B. 2003. Fifty years of bird song research: a case study in animal behaviour. Animal Behaviour, 65, 633-639.

Smolker, R. A. \& Pepper, J. W. 1999. Whistle convergence among allied male bottlenose dolphins (Delphinidae, Tursiops sp.). Ethology, 105, 595-617.

Smolker, R. A., Mann, J. \& Smuts, B. B. 1993. Use of signature whistles during separations and reunions by wild bottlenose dolphin mothers and infants. Behavioral Ecology and Sociobiology, 33, 393-402.

Steiner, W. W. 1981. Species-specific differences in pure tone whistle vocalizations of five western North Atlantic dolphin species. Behavioral Ecology and Sociobiology, 9, 241-246.

Strager, H. 1995. Pod-specific call repertoires and compound calls of killer whales, Orcinus orca Linnaeus, 1758, in the waters of northern Norway. Canadian Journal of Zoology, 73, 1037-1047.

Theberge, J. B. \& Falls, J. B. 1967. Howling as a means of communication in timber wolves. American Zoologist, 7, 331-338.

Thomsen, F. \& Ford, J. K. B. 1999. Behavioural significance and structure of whistles from wild killer whales (Orcinus orca) in the waters around Vancouver Island, British Columbia. In: European Research on Cetaceans: Proceedings of the 12th Annual Conference of the European Cetacean Society, January 20-24, 1998, Monaco (Ed. by P. G. H. Evans \& E. C. M. Parsons), pp. 262-265. Valencia: European Cetacean Society.

Thomsen, F., Franck, D. \& Ford, J. K. B. 2001. Characteristics of whistles from the acoustic repertoire of resident killer whales (Orcinus orca) off Vancouver Island, British Columbia. Journal of the Acoustical Society of America, 109, 1240-1246.

Thomsen, F., Franck, D. \& Ford, J. K. B. 2002. On the communicative significance of whistles in wild killer whales (Orcinus orca). Naturwissenschaften, 89, 404-407.

Tyack, P. 1986. Whistle repertoires of two bottlenosed dolphins, Tursiops truncatus: mimicry of signature whistles? Behavioral Ecology and Sociobiology, 18, 251-257.

Tyack, P. 1998. Acoustic communication under the sea. In: Animal Acoustic Communication (Ed. by S. L. Hopp, M. J. Owen \& P. Evans), pp. 163-219. Berlin: Springer Verlag.

Tyack, P. \& Clark, C. W. 2000. Communication and acoustic behaviour of dolphins and whales. In: Hearing by Whales and Dolphins (Ed. by W. W. L. Au, A. N. Popper \& R. R. Fay), pp. 156-225. New York: Springer Verlag.

Tyack, P. \& Sayigh, L. S. 1997. Vocal learning in cetaceans. In: Social Influences on Vocal Development (Ed. by C. T. Snowdon \& M. Hausberger), pp. 208-233. Cambridge: Cambridge University Press. 
Waser, P. M. 1975. Individual recognition, intragroup cohesion and intergroup spacing: evidence from sound playback to forest monkeys. Behaviour, 60, 28-74.

Watwood, S. L., Tyack, P. L. \& Wells, R. S. 2004. Whistle sharing in paired male bottlenose dolphins, Tursiops truncatus. Behavioral Ecology and Sociobiology, 55, 531-543.
Weilgart, L. \& Whitehead, H. 1997. Group-specific dialects and geographical variation in coda repertoire in South Pacific sperm whales. Behavioral Ecology and Sociobiology, 40, 277-285.

Yurk, H., Barrett-Lennard, L., Ford, J. K. B. \& Matkin, C. O. 2002. Cultural transmission within maternal lineages: vocal clans in resident killer whales in southern Alaska. Animal Behaviour, 63, 1103-1119. 